\title{
Administrative Responsibility and Moral Action: Are These Workable Panaceas for Strengthening the Competency Paradigm in Nigeria's Public Service
}

\author{
Akume, Albert. T \\ Department of Public Administration, \\ CASSS, Kaduna Polytechnic, Kaduna State-Nigeria \\ yimaalbert@yahoo.com
}

\section{Doi:10.5901/mjss.2014.v5n10p31}

\begin{abstract}
The real value of government and her public institutions to the people lies in her ability to formulate policies, mobilize resources for their implementation and deliver public service in an ethically responsive and effective manner. In Nigeria's case the need to provide public service prudentially seems to evade government and her public institutions. For the government, the failure is due to her public institutions' incompetence. Ironically, public institutions' incompetence is a consequence of government failure to relate with them ethically. The consequence is reflected in the disrespect for good work ethics and poor service delivery. This paper argues that government capacity to relate ethically with her public institutions will in turn trigger in them the desire to be ethically responsive to deliver public service better to Nigerian.
\end{abstract}

Keywords: Competence. Administrative Responsibility. Ethics. Work Ethics. Moral Action. Service Delivery.

\section{Introduction}

Public organizations or institutions are designated to serve the public space. They are specifically responsible to facilitate the development of the state through effective policy implementation for the common good. Although, this institution of the state have intrusive powers due to the nature of state responsibilities assigned to it; in Nigeria, however, most people often associate public institutions with inefficiency and pointless and time-consuming formalities (Heywood, 2006:357). Despite this poor perception, it is however evident that this institution of the state cannot be dismissed by a mere wave of the hand as irrelevant by the citizenry because of the important function they perform for the state. The roles they serve are capsuled in carrying out policy administration; offering policy advice; articulating and aggregating interest; political stability and state continuity (Heywood, 2006:363-365) and a standing link between the citizenry and the government. Within the realm of governance, in whatever, society public organizations are a lasting, enduring and continuing institution. Heywood is however quick to argue that institutional continuity can also have its disadvantages despite the advantages it has. This is because in the absence of effective public scrutiny and accountability undoubtedly leads to corruption. This is clearly an indisputable true observation if the case of Nigeria is brought into context.

Public organizations are part of the broader structures of government. Its template for operation is defined by the manifesto and development focus of the government in power. Public organizations are by no means an end in themselves but a function of service that is predicated on neutrality, fairness, effectiveness and efficiency. Public organizations are a social system defined within the value orientation model of Kluckhohn and Strodtbecks as elaborated by (Punnett, 2001). Using the Kluckhohn and Strodtbecks models, it is argued that public organizations seek internal harmony and mastery of the external environment; their search for solution to solve public problem is defined by time orientation; have a mixed assumption of human nature; activity oriented; and designed to operate in tandem with human relationship (Punnett, 2001:16-19). Public officials or administrators are key element within the mainstream structures of public organizations. Administrative officials are designated workhorse responsible for implementing policies and procedures and ensuring that public organizations are well-managed and positioned to deliver the right service to the people. They are responsible for implementing policies and procedures that allow public institutions to comply with applicable laws and regulations, uphold the public trust in a manner that reflect appropriately the interest of social diversity.

If management has a positive view of its public organizations then, its culture will be directed at designing rewards that would be closely related to current performance; facilitate participative management, decisions are likely to be intuitive with less concern for logic and organizational structure will reflect a formal authority-based hierarchy (Punnett, 
2001:17). It is however evident that societal culture and values are not homogeneous even in an ever globalizing world as ours, it should therefore be expected that societal culture impact and outcomes on public organizations are likely to vary given that societal values differ and cultures are subject to change (Cray, 2001:6) but they in significant ways influence public organizational planning and service delivery. Given this understanding, management should allow openness given that the world is not the world you know and accept is constantly necessary (Punnett, 2001:25). This will facilitate better interaction, resource organization and use in order to achieve result with less strain. This in part is a fundamental recipe for sustained service delivery that is effective and efficient in tandem with public interest.

Alongside the above, at the individual employee level, it is imposing upon employees' of public organizations to be competent and rational in the discharge of their duties. Rationality presupposes the use of sound reasoning rather than emotions in making decisions. Rationality is an essential character for public officials in making decisions about the right use of public resources and balancing conflicting public interest in a significantly diverse society. Rationality is a key instrument necessary for building a reliable, predictable and, above all, efficient means of social organization (Heywood, 2006:357). The unanimous acceptance of the rational element is however punctured by the fact that man in decisionmaking is not absolutely value-free or neutral (Henry, 2007:399). Equally not leaving the rationality issue unquestioned or scratch-free is the fact that man in the process of decision-making seldom have at his disposal all the time, information neither has the administrator the mental capacity to reasonably evaluate all options and their outcome so as to evolve the most rational choices. Nevertheless, the rational view is useful in providing a benchmark against which to compare actual managerial decision-making patterns (Bartol and Marton, 1998:142).

Competence subsumes skills, knowledge, behaviours and successful performance. Competencies are supposed to be discrete and cumulative, with each level building on the level below (Civil Service Human Resources, 2013:1). Competent public officials are indispensible in decision-making, for mobilizing and issuing directive in the best use of resources, organization, creating social order in the work-place and goal attainment. It is against this backdrop that most public officials can no longer be dismissed as mere administrators or policy implementors; because, they are key figures in the policy process, and even sometimes run their countries (Heywood, 2006:357). An administrator's capacity to act competently can be undermined by several factors. Significant among the factors that inhibit organizational competence is the inability of the organization to adapt its human resource practice to the characteristics of local personnel (Juha and Gyursansky, 1998) conditions. Equally too, competence is impinged upon when management or government fail to introduce genuine equality of opportunity and humanize the work place (Derek, et. al 2005:722). Albeit, competency and rational action are veritable instruments that public officials' need to help them walk through the twist and turn of unethical countervailing and turbulent waves of political intrusiveness to deliver selfless services that are socially aligned with, and that suit the diverse needs of the population within limited state resources.

Given the high inflationary trend in Nigeria since the introduction of Structural Adjustment Programme in 1986, there are no better human resource practices that will motivate and enhance commitment and competent performance from Nigerian public employees better than a just and commensurate wage and salary regime. Any right effort in that direction will reduce the increasing waves of trade disputes, motivate Nigerian public employees to work better and help them to adapt to changing economic conditions that have reduced the value of real income in Nigeria. This fact was aptly captured in Shonekan's Committee recommendation for $10 \%$ annual increase in salaries of public employees' over the next ten years (Okonjo-Iweala and Osafo-Kwaaka, 2007:14) to reflect changing economic realities in Nigeria. One cannot hide the fact that present local economic conditions in Nigeria dictate that government should be open and just to her employees, improve the poor remuneration paid employees (Okonjo-Iweala and Osafo-Kwaaka, 2007:14), reduce the wide salary disparity between public servants and political office holders in Nigeria. The glaring reality of government bias and injustice could be deduced from Onyekpere (2013) allegation on an AIT television chat show on the high cost of governance that 18, 000 senior political officials of the federal government were maintain with a whooping \#1billion naira while the National Assembly from 2005 to date had divert a total of \#1trn for its upkeep (Guardian, 2013 and Odewale, 2013:30).

His assertion is collaborated by Ezekwesili (ilevbare.com, 2013) and the Nigerian Central Bank Governor Sanusi, Lamido Sanusi. According to Ezekwesili the nation's presidency under the late Umaru Musa Yar' Adua and the incumbent President Goodluck Jonathan, had within the last six years, squandered substantial part of the \$45billion left in foreign reserves of the country by president Olusegun Obasanjo in May 2007 as well as $\$ 22$ billion the Excess Crude Account. These monies are purportedly used for overhead cost and employee welfare; it did not include the mass of Nigeria's public employees who daily bears the burden of state administration. The painful side of the whole issue is that public servants who constitute the bulk of the nation's workforces are paid salaries that can barely get them by (Odewale, 2013:30); but are however passed the bulk of the blame of been incompetent and corrupt, lacking the innovativeness and managerial skill to stimulate growth attainment (lyayi, 2004:289). 
This assumed incompetence cannot be divorced from the gross inequity in the system evidenced by a wide variation between the salaries of political officeholders and those of the permanent public official. This unexplainable huge wage divide reclines behind the soared relations between public employees and the government. Its poor handling has triggered a counter reaction evidenced in delivery of public service by public employees that is characteristic of malfeasance, misfeasance and nonfeasance. To worsen the situation the federal government has adopted amoral schemes to evade meeting the demand of public union's for balancing the wide wage divide in Nigeria. The derisive manner in which the government has chosen to handle her public employee grievance has resulted in counter-punching between the latter and government. It is pertinent to note that the action of government and the counter reaction of public employees are both unethical; as the outcome reflects a saddening scenario were public service delivery in Nigeria continues to be compromised.

This is not to say that Nigerian public officials are incompetent and cannot act rationally; however, most public officials due to unjust wage and salary regime have chosen to act irrationally against public good. This is an incontrovertible truth as Okonjo-Iweala and Osafo-Kwaako, (2007:14) observed that a weak incentive structure in the civil service which did not foster good performance, resulted in a weak work ethic and poor service delivery by many ministries, often characterized by hidden or outright corrupt behavior on the part of many civil servants. The amoral response to the genuine demands for salary balance and equity by government raises the ethical question of fidelity, honesty, justice, nonmaleficence, control, accountability, responsiveness and responsibility to her employees and the general public. While, the counter reaction of public employees which hamper better service delivery raises the ethical question of beneficence, reparation, the principle of harm, social benefit, paternalism, lawfulness and benevolence to the general public.

It is from this angle that administrative responsibility and moral action fit in as vital ethical tools for provoking government and public employees to adopt more responsive attitude in dealing with issues that affect the public when they disagree over interest or conflict. Administrative responsibility is aimed at raising and maintaining a high ethical bar of accountability, responsiveness, responsibility and control. These elements facilitate public officials' greater responsibility to elected supervisors, greater responsibility to community groups and greater commitment to value and higher standard of morality (Etzioni in Nnaji, 2001:80); so as to avoid personal liability (Rosenbloom, 2009:533) that evolve from self-centric focus. In the performance of public responsibilities, administrative officials may delegate certain administrative and financial duties to others against established expectations and standards. While it is sometimes expedient that administrative officials delegate many of their responsibilities, they cannot delegate accountability (UC, 2013:8). It is for this purpose that public officials retain accountability over the area of responsibility assigned to them as individuals as long as they remain with any public organization. Collectively, their actions portray a valued reality of the rule by officials that lie behind the façade of representation and democratic accountability (Heywood, 2006:357) that is indispensable either to the state or the citizenry.

The requirement for public officials to be accountable is not only tied to the need to act in accordance with expected standards but to also ensure that their use of public resources, authority and discretionary powers are not abused or are not used to subvert the public interest, neither does their used cause harm to state resources nor the people. It is argued that for a high standard of public service delivery to be achieved and sustained, public officials are required to display honesty, transparency alongside internal and external accountability (Kanyane, 2010:81). Accountability is guaranteed in any system when the level and mix of government spending and the distribution of its cost are decided in a climate of full disclosure. The internal accountability ensures that public officials are answerable to their line supervisors for their own actions and the actions of their subordinates, while external accountability hold public officials answerable to the public (Kanyane, 2010:81). Accountability is an open catch-all action word that overshadow fiscal, legal, programme, outcome and political accountability. These five dimensions of accountability have been collapsed into political, administrative and fiscal accountability. Enforcing these accountability dimensions is aimed at ensuring that political and administrative entities are not beyond the control of other entities in checks and balances, systems, or, beyond the reach of the consent of the governed (Amoke and Asogwa, 2001:147). Although, public officials are directly accountable to their executive authority and administrative authorities for their action and activities, it is incumbent upon them to ensure that they are also accountable to the consumers of the public service they render (Kanyane, 2010:81).

The basis of moral accountability is to facilitate state progress given that government and its administrative agents hold their position of power in trust for the people. A good accountability system facilitates better public service delivery by ensuring that the governance system in place is responsive to the needs of the people (Kanyane, 2010: 81). Similarly too, the need for such control is conditioned by the fact that human action if unchecked is inclined toward self-centric and self-serving tendencies that impinge detrimentally on public service delivery and national development. The saddening 
degeneration of ethical value, bureaucratic corruption and poor work ethic evidenced by poor service delivery in Nigeria cannot be divorced from the absence of a sincere political will to enforce the higher standard of ethics, administrative responsibility and moral action in Nigeria's public administration. It is no wonder that the cost of providing public service is still on the high side, poor service delivery, an exploited citizenry and gross abuse of public resources and administrative procedure are pervasive in governance system in Nigeria (Adebayo, 2000, Otobo, 2002 and Adamolekun, 2006).

There is no doubt that the level of institutional decay, incompetence and level of corruption in an institution or system is conditioned by a variety of factors, including the effectiveness of external checks, the level of administrative discipline, and the strength of internal codes and norms (Heywood, 2006:365). These better service delivery inhibitors can in part be corrected by ethical force that reclines behind administrative responsibility and moral action. Unfortunately, due to the gross poor work ethic and poor service delivery the competence of Nigerian public employees is continually being questioned. The cumulative impact of all these weakness is that despite Nigeria's huge human and financial resources potentials the country's development efforts have been painfully slow and costly. It is in the light of the above that, in recent decades, ethics has taken on a new importance, in part, because of the widespread public cynicism about government and a pervasive distrust that almost invites government employees to be anything but ethical in their daily activities and operations. Lack of public trust and confidence can have significant impact on the future of public service profession (Haque, 2004:702).

It is against this backdrop that this paper using the documentary and analytical approach examines the relevant place and impact of administrative responsibility and moral action in strengthening public organizational competence in Nigeria.

\section{Competence and Administrative Responsibility: Is There Any Relationship?}

Competence is a necessary dimension for any organization that strives to be effective and efficient. As organization strives to become more successful and less crises prone, it is necessary for them to prioritize their competences (Thompson, 2004:141-142). Competence provides the organization the most appropriate arena and capacity to express itself by performing rightly task assigned in order to attain stated goals. From a narrow perspective competence is the necessary skills individual employee possesses that aid them to perform assigned task without difficulty and less supervision. It encompasses an individual's technical and interpersonal knowledge and skill (Robbins and Judge, 2008:424). A more comprehensive meaning of competence however goes beyond merely possessing the right skills, it include the ability to perform particular activities within an occupation to a prescribed standard...it also include the set of behavior patterns that the incumbent needs to bring to a position in order to perform its tasks and functions (Gold, 1999:184). On the whole, it reflects the individuals overall capability to undertake certain work (Cole, 2006:163). Possessing requisite sets of skills, abilities and capabilities to perform one's responsibility represents individual competence. Competencies are broader concepts that subsume demonstrable performance outputs and behaviour inputs relative to a system or set of minimum standard required for effective performance (CIPD, 2013 and NPC, 2012).

At the heart of the competence discussion is the tripartite qualities of skill, behaviours and standard performance. These three recline behind the competency framework. it is argued by scholars like Boam and Sparrows, (1992:13) that competence frameworks lies at the heart of all approaches to HRM in that it forms the basis for integrating HRM processes (Gold, 1999:185) evaluation, selection, development, promotion, and reward of employees (Robinson, et. al, 2007:66) in an organization. These HRM processes are weaved into one mold by an organization's culture; which if configured and managed rightly influence positively employee behaviour and working environment (Grover, 2008:466467). Organizational culture defines the dominant value system in an organization and when properly internalized by its members, it has important effect on organizational competence. The positive influence organizational culture has on employees and working environment is derived from the trust that competence generates between employees and management. This is what Robbins and Judge, (2008:425) refer to as knowledge base trust; and it is established based on the behavioural predictability that comes from a history of interaction.

In the extant literature, most scholarly emphasis has been on personal competence model over other types of competencies models. There are four distinguishable sets of personal competency. The four models are: i) planning to optimize the achievement of results; ii) managing others to optimize results; iii) managing oneself to optimize results; iv) using intellect to optimize results (Cole, 2006:163-164). Aside from personal competency there are four other identifiable competency model which are: i) organizational also referred to as generic or core competency; organizational competency model subsumes those competencies required of all employees in the organization; ii) functional competency model relates to the standards of performance needed by an individual working in a specific role or function; iii) job competency model typically encapsulates specific behaviors, skills and knowledge sets required for exceptional 
performance on a specific job; and iv) leadership or managerial competency model denotes the factors that lead to success for company leaders, senior staff, executives, and others who fill top management or leadership roles (Schieltz, 2013).

For Grobler, et. al. (2005:177) organizational competencies can be grouped into three typologies which are: management, individual and teamwork. All other categorizations of competencies neatly fit into the competency typologies already mentioned above hence it is irrelevant to restate them again so as to avoid unnecessary regurgitation. Two types of competencies are associated with organizational competency; they are core and strategic competencies. An organization's core competency is derived from the combination of the company's individual technologies and production skills that underlies a company's product lines, while Strategic organizational competency provides the company with distinctive capabilities (Grobler, et al., 2005:177) necessary to perform its function appropriately. Quintessentially, it is by an organization developing these competencies that it could attain the competitive edge to stay ahead of its rivals and the environment.

These typologies of competences have further been subdivided into surrogates' thus providing us an illuminating description of standards or factors that contribute toward success along with behavioral or organizational anchors that can be measured and assessed (Schieltz, 2013). Thinking along this line, Cole, (2006:164) borrowing from the work of Boyatize, (1982) noted that competences have twelve characteristic that express themselves in very general terms. These twelve competencies are related to; concern for impact; diagnostic use of concepts; efficiency orientation; proactivity; conceptualization; self-confidence; use of oral presentation; managing group processes; use of socialized power; perceptual objectivity; self-controls; and stamina and adaptability.

Others are; strategic perspective, appropriate software and hardware technologies, product quality, cost effectiveness, change management, knowledge ability and competence of individuals, effectiveness and efficiency of operations, internal and external coordination, and integration (Habib, 2012:188). These competency elements are relative similar to the main characteristic of agility (Stekelenburg, 2012:2). This linkage has significantly blurred the line dividing competence and agility. It is thus evident that competence provides the firms (organizations) the option to be agile depending among other things innovation (Ravichandran, et al., 2007:3) proactivity, adaptation and generative abilities (Dyer and Shafer cited in Stekelenburg, 2012:7). In a capsule, the use of competencies serves to enhance an organization's performance and therefore yields a competitive advantage due to increased employee productivity, reduced training cost, and reduced staff turnover (Robinson, 2007:66)

The question then is how can public organization develop the competencies of its employees as a necessary precondition for the overall competence of such public organization? The starting point is by adopting the competency framework which sets out how we want people in the civil service to work. Those three strategic competency clusters are: i) setting direction (seeing the big picture, change and improvement and making effective decisions), ii) engaging people (leading and communicating, collaborating and partnering, and building capability for all) and iii) delivering results (achieving commercial outcomes, delivering value for money, managing a quality service and delivering at pace) (Civil Service Competency Framework, 2013:1, 3-5). For the public service the competency framework can be collapsed into three distinct but interrelated groups anchored on the civil service values of honesty, integrity, impartiality, and objectivity in service.

For Denhardt and Denhardt the answer to the question can be found in building a learning organization. Supporting the learning dimension in facilitating organizational competency Lenin emphasized that we must at all cost set out, first, to learn, to learn, and thirdly, to learn, and then see to it that learning shall not remain a dead letter, or a fashionable catchyphrase...learning shall really become part of our very being, that it shall actually and fully become a constituent element of our social life (Sapru, 2008:303). Following through with the learning dimension is the need for checks, supervision, control, accountability and responsiveness; these elements constitute the enduring character of administrative responsibility. These ethical values are relevant in guiding and strengthening the administrator sense of responsibility in process of utilizing his/her skills, knowledge and competence in the place of public service. Supporting this line of thought Lenin argued that the first task of the moment is not decree, not reorganization, but selection of people; establishment of individual responsibility for what is being done; checking up on work actually performed (in Sapru, 2008:303). This kind of efforts are essential for strengthening better work ethic and providing a motivational dynamism that get things done (Heller, 2001:331).

Building a learning organization is more than mere rhetoric's, it requires personal mastery; mental models; shared vision; team learning; and system thinking (Senge cited in Denhardt and Denhardt, 2009:181) overlaid by leadership's enduring commitment to its success. While for some scholars, the answer is tied to the right configuration of organizational resource-based strategy (Thomson, 2004:56). He further argued that for competencies to be developed requires: i) the organization behaving in a co-ordinate, synergy-creating manner, integrating functions and businesses; 
and ii) value adding network to be managed as an effective, integrated, system (Thompson, 2004:56). These processes are to be executed internally, based on system thinking and externally, through the establishment of linkages or even alliance between organizations at different stages of the added value chain (Thompson, 2004:60).

Thompson, (2004) however cautioned that although an organization's resources constitute both opportunity and strength for competitive advantage yet, they can represent threat for the organization if it is not configured and utilized properly. Hence, it is by management leveraging organizational resources along the right lines that organizational competence is guaranteed. This is a fundamental requirement for organization that wants to avoid organizational decline, to be forward-looking, while at the same time remain effective in attaining their goal. For miller, (2013:2) evolving a competent organization starts with the utilization of the balanced approach to employee selection (sourcing). According to him, abalanced approach in which an agency executive is selected through the politicized process and subordinates are selected through a politically autonomous (merit) process or vice versa produces the greatest benefit for bureaucratic competence. The balance between politicized and politically-autonomous personnel system allows an agency to benefit from the performance advantage of each type of personnel system and attenuate potential detrimental effects.

The importance of the balanced approach according to Miller, (2013) is that an elected executive is directly accountable to voters for performance (and other actions) of a single agency, while appointed executive is only indirectly accountable to voters through the appointing official(s) who is responsible for the performance(and other actions) of many agencies. The more narrowly-defined responsibilities of elected agency executives enhance accountability which may have implications for the performance of agency under the control of elected executives.

While the idea behind the above mix is plausible, the efficacy of its application in an arbitrary governance and administrative system as is the case with Nigeria is questionable. Conversely, if however the Nigerian state is able to adopt and adhere to the fundamental principle of discipline, order and the rule of law the implementation of the above idea will result in high administrative efficiency and responsiveness. To be specific, this idea (mix) was implemented as part of the process of reforming the Nigerian in 1988 by the Babangida military regime as a panacea for solving the disturbing deficiency of the nation's bureaucracy. Sadly, the result proved rather counter-productive (Akume, 2012:40). The reason for its disastrous failure was that the implementation of the balanced approach was not backed-up by the institution of a democratic environment it needed to create the right effect on Nigeria's public bureaucracy. Irrespective of the complexities, it is evident that to hold the competent edge necessary for efficient service delivery in a turbulent and volatile environment no organization can over-look the need to possess all the competency dimensionality identifiable in the literature.

While the above may be reasonably important for operational effectiveness of public organization, it is expected that public organizations design and operations are defined and directed by three clusters of administrative values to ensure competence. These clusters of values are generally referred to as the sigma, theta and lambda family. Accordingly,

In the sigma family come administrative values connected with the matching of resources to narrowly defined tasks and circumstances in a competent and sparing fashion... The theta-type connotes values broadly relation to the pursuit of honesty, fairness, and mutuality of through the prevention of distortion, inequity, bias, and abuse of office...lambda-type values relates to resilience, endurance, robustness survival, and adaptivity- the capacity to withstand and learn from the blows of fate, to avoid competency traps in adaptation process, to keep operating even in adverse worst case condition and to adapt rapidly in a crisis... broadly, the sigma family of values relates to economy and parsimony, the theta family relates to honesty and fairness, and the lambda family relates to security and resilience (Hood, 2007:500-504).

It is essential to note that if the sigma-type values are emphasized, the central concern is to trim fat and avoid slack... if theta-type values are placed at the center stage, the central concern is to ensure honesty, prevent capture of public bodies by unrepresentative groups, and avoid all arbitrary proceedings...if the lambda-type values are placed at the center stage, the central concern is to avoid system failure, down time, paralysis in the face of threat or challenge. Even a cursory look at these values, it is evident that they are not only related but important for public organization effectiveness. Hence, it cannot be claimed that these values are esoteric or extreme, or that they are not administrative values (Hood, 2007:500). The one fundamental tying point of competence, administrative responsibility and moral action from the above identified clusters is theta-type family administrative values where attempt to socialize public servant in something more than bottom line ethics or high grovel count. From this viewpoint, success is counted in terms of rectitude, the proper discharge of duties in procedural and substantive terms, while failure is measured in terms of malversation in a formal or substantive sense (Hood, 2007:502).

Enhancing organizational competency requires management empowering its employees. Scholars have different opinion with respect to the concept of empowerment in organizational setting. Albeit, empowerment can be seen as a form of employee involvement with the intent of garnering their commitment in order to contribute to organizational 
development; through direct involvement in work practices rather than indirect (Wilkinson, 2001:509). Empowerment relates to management practice of sharing information, rewards, and power with employees so that they can take initiative and make decisions to solve problems and improve service and performance. Empowerment is based on the idea that giving employees skills, resources, authority, opportunity, motivation, as well holding the responsible and accountable for outcomes of their actions, will contribute to their competence and satisfaction (BusinessDictinary, 2013). employee empowerment agenda in the organization will demand management Initiating, implementing and sustaining these internal organizational culture and practice of information sharing, upward problem-solving, task autonomy, attitudinal shaping, and self-management (Wilkinson, 2001:509-511). Employee empowerment is an essential pathway to administrative efficiency.

Organizational competency cannot be divorced from administrative efficiency the latter concept is an integral element necessary for strengthening the former. Efficiency denotes doing things right (Bartol and Martin, 1998:17). It is expressed as a ratio of input over output (Henry, 2007:146). Put together, it denotes getting the most output from the least amount of input (Grover, 2008:18). The need to facilitate public organizational competence and efficiency has provoked the search for the right mix of structural arrangement and management methods that will rightly weave together available organizational scarce resources to solve or at least, alleviate community problems. The different answers to this search beginning from the classical to the contingency school of management thoughts have been encapsulated in principles. According to Herbert, (1941:53) the more common "principles" that occur in the literature of administration are that:

i) administrative efficiency is increased by a specialization of the task among the group;

ii) administrative efficiency is increased by arranging the members of the group in a determinate hierarchy of authority;

iii) administrative efficiency is increased by limiting the span of control, at any point in the hierarchy to a small number;

iv) administrative efficiency is increased by grouping the workers, for purposes of control, according to (a) purpose, (b) process, (c) clientele, or (d) place.

From the above, it is clear that identifying the right structuring that is most appropriate for an organization is dependent on the nature of the organization and the kind of responsibility assigned to it. It then means that decentralization rather than centralization in a federal state will facilitate better service delivery given the nature, divergence, coverage area and nature of benefit of the various services to be delivered. The most appropriate pattern of configuring these principles so as to enhance the efficiency and competence of public organization will then depend on the managerial competence of the management team of that organization.

The best kind of structural and organizational arrangement is one that enhances an organization's capacity to be flexible responsive and adaptive to change thereby facilitating its administrative, policy and service efficient. Administrative efficiency is focused on good organization, appropriate methods, and procedures and the use of management techniques such as work study, network technique etc. policy efficiency aims at making the right policy decision and the choice of appropriate programmes to achieve defined objective. Service efficiency focuses on satisfying the public (Mohit, 2006:35-36). Making public organization produce the right result along these lines requires government concerted efforts at provoking adjustments in the organization in commensurate dimension to achieve a PersonEnvironmental fit (needs-supply fit and demand-ability fit) and the interrelationship among them such that employees adapt to changes in job demand, remains loyal and committed to the organization (Caplan, 1987:249-250). The measure of success, in part, will depend on the national principles, peer condition, custom and institutional commitment (Haque, 2004:702) provoked by a far wage regime.

Paradoxically, even though these principles appear relatively simple and clear, it would seem that their application to concrete problems of administrative organization would be unambiguous and that their validity would be easily submitted to empirical test. Such, however, seems not to be the case (Herbert, 1941:53). Simply because, subjecting these principles to critical analysis it is evident that none of the four can survived in very good shape; for in each case there was found, instead of an unequivocal principle, a set of two or more mutually incompatible principles apparently equally applicable to the administrative situation (Herbert, 1941:61). It may be for this reason that public organizations in developing societies like Nigeria have hinged their institutional arrangement on the more easy methods of the Weberian bureaucratic prescription that have been criticized to be rigid and inefficient.

Relocating our focus from the complexities of organizational structuring is the imposing question of what import is competence to the administrator if he/she lacks a sense of administrative responsibility and moral action to act and serve in a trustworthy manner by providing the right service to the people as envisaged by the public. This question is apt against the backdrop of the assumed prevalence of competent human resources, institutional and legal frameworks that 
the Nigerian bureaucracy posses yet the citizens and the Nigerian-state have been short-change continually due to poor service delivery. This failure has over time called for the exercise of the ideals of ethical administrative behaviours inherent in the doctrine of administrative responsibility by administrators in Nigeria. This call is premised on the belief that it will make administrators to be responsive and pro-active to issues of public service delivery given clear lines of accountability and sharp definition of purpose (lyayi, 2004:295). This will allow the government to effectively harness the potential performance advantages of responsiveness competence (Miller, 2013:2) from her public organizations.

\section{Administrative Responsibility: Does It Fit in Rightly to Facilitate the Competency Paradigm?}

In a bid to identify and utilize a one-fit conception of administrative responsibility to guide this work, one is not oblivious of the very real problem of been caught-up in the conflicting milieu of discordant opinion that characterize scholarly divide about what administrative responsibility really is. This is because the various definitions of administrative responsibility have continued to dance to the different rhythm of different approaches. That not withstanding, proponents of all the approaches have evidenced a central concern with the problem of "administrative responsibility." For some the term "administrative responsibility" has stood for the putatively democratic and political dimensions of public administration, for others the same term has stood for central attributes of the concept "bureaucracy," for others the term has chiefly to do with the "rule of law" and distinctively legal apparatus, and for still others it stands for attitudes and patterns of individual and group behavior in administration and its environment about which we know little but which we can best adumbrate in the language of social psychology (Gilbert, 1959).

According to Grover, (2008:157) administrative responsibility is better understood within the precincts of responsiveness, fairness, flexibility, honesty, accountability and competence. These values have been reconfigured to reflect honor, benevolence, and justice. Honor imposes upon the employer and the employees to adhere to the highest standards of responsibility, integrity, benevolence and principles in relations and service. Benevolence is the disposition to do good and to promote the welfare of others. Justice is treating others fairly and respecting the rights of others (Rosenbloom, 2009). These values should be capsuled in a value chain quality that will produce a competent workforce that the people would like to see in their government organizations.

The whole essence of administrative responsibility is to evoke an ethical side of governance that is both responsive to the people's will as well as one that is equally responsible for his/her action during and after public service has been rendered. In which case, it is expected that the administrator exercise discretion in a manner that is consistent with the best professional practices (Rosenbloom, 2009:533) that support better business and good government (Henry, 2007:397). In public life, especially organizations, the problem of identifying the moral agents, of finding the persons who are morally responsible for a decision or policy, becomes at least as difficult as the problem of assessing the morality of the decision or policy (Thompson, 2007:456). The problem is very real given the multiplicity of administrators and organizations involved in decision-making in the public place. This problem is further compounded by the argument that no individual is a necessary or sufficient cause of any organizational outcome, the second is the gap between individual intention and collective outcome, and the third is the problem of role. If we were to accept these arguments, we would let many guilty officials off the moral hook according to (Thompson, (2007:456-457). Despite the plausibility of those arguments administrative ethic is possible.

In the face of such real ethical dilemma in the public place, the ethical dimension of administrative responsibility becomes a valid instrument for regulating rightly the conscience and conduct of the administrator in the place of public service. While the concept has the capacity to insulate the administrator from falling into the value-deficiency trap during decision-making that could adversely affect performance and service delivery; it does not however stop him/her from the ever increasing barrage of conflicting demand of loyalty that is faced by the administrator in time of decision-making in the discharge of his/her duty. This conflicting situation that confront a public manager according to Denhardt and Denhardt, (2009:135) relates to the potential conflicting demands of operating as efficiently as possible while, at the same time, being fully responsive to administrative superiors, to the legislature, to the citizenry, and to the principle of democratic governance generally. Aside from the above challenge it is also true that the concept of administrative responsibility is riddled with contradictions such as administrative neutrality. Similarly, such contradictions are evident in the administrator's efforts to enhance fairness, honesty, and accountability may be at odds with the ideals of responsiveness, flexibility, and competence. These contradictions have never been more acute than today (Grover, 2008:170).

It is in pursuant of good government that it is comforting to know that public administrators take ethics and their practice seriously, and that ethical government may equate with more efficient and effective government (Henry, 2007:397). While this observation may be an open one and subject to disputation, it is however true that adhering to the right ethical standard is vital for trust building, good administration and good governance relations. The soundness of this 
concept and capacity to insulate the administrator from inhibiting anti-good administrative elements is not in doubt. This form of shield is a life saver for the administrator because public administration is a profession that offers an unusually rich variety of opportunities to make a moral or immoral decisions, to make ethical or unethical choices, to do good or evil things to people (Henry, 2007:403).

To be specific, ethics is meant to safeguard the integrity of the organization by helping individuals' conform to professional norms, avoid mistakes and misdeeds that violate the public trust, and ensure that public officials in a constitutional republic are accountable to the people through their elected representatives (Guy and Balfour, 2007:566). The choice to act amoral or unethical will significantly depend on the degree of personal and social values held by the administrator. It is also appending to the knowledge by the administrator that his/her action in the place of service will be questioned and that the cost of been found to be amoral far exceed the benefit that is derived from such amoral act. To effect this end the state must have a standing legal system that is responsive in dispensing justice speedily in a manner that discourages crime in a manner that is devoid of fear or favour.

\section{What Is Moral Action and How Does it Fit in to Energize Administrative Responsibility and the Competency Paradigm in Nigeria' Public Organizations?}

Nigeria's government insincerity of purpose to uphold the time-honoured ethical value of honesty by abiding to jointly agreed terms calls to question the moral uprightness of the state to be trusted by her workers to protect their interest. Sadly, government has failed to understand as evidence indicates that employees do not simply buy into rhetoric in an unconditional way and their support is dependent upon trust in management and the perceived benefits to themselves (Wilkinson, 2001:515); which in Nigeria case is lacking towards management and government. Morality is not only defined by determining what is right but also acting upon that which is defined right for the good of other even when the enforcer has the power to go contrary to that good action when it is not in his/her interest.

Morality is concerned with those practices and activities that are considered right or wrong; it is also concerned with the values those practices reflect and the rules through which they are carried out. The morality of a society, a political organization concerns with what is considered to be right or wrong within that group. Morality expresses certain values that members of the group hold to be important and is reflected in laws, rules, and regulations, or in policies and procedures. Moral action, in turn, is action that is consistent with the groups morality- that which expresses the group's most basic commitment about what is right and what is wrong (Denhardt and Denhardt, 2009:127).

Aside from the dimension of group morality, moral action relate to individual voluntary action of an intelligent agent, who is capable of distinguishing between right and wrong, or of distinguishing what he ought, from what he ought not, to do (Wayland, 2013).

Integrity is an integral element in morality and the foundation for building true character for a mutual beneficial relationship. It strengthens the spirit of genuine service and self sacrifice in the place of public authority. It is the foundation and force that does not merely hold on to the basis of what one belief to be right, but act on the basis of that belief that is right and good. Without integrity or nobleness of character that promotes justice, equality and respect for the dignity of society there will be greed and self-centric personalization of state power and resources. These are latent human character that causes the reasonable rights of others to be undermined. Under such circumstance state resources are converted for private use to the detriment of the majority as decision about public good are subverted with implications for inequity and exploitation. To overcome the dilemma and consequence of such moral decay demands the strengthening of moral action in government. This is vital in eliminating dishonesty, the abuse of the rule of law and discrimination in the distribution and enforcement of the rights of employees. It is from this angle that the Nigerian government and her political officeholders cannot be exonerated from guilt.

While the problem of discrimination can be reasonably resolved through the meditative process of collective bargaining between public union leadership and the government; the character of the latter to go into agreement with a hidden intent of reneging on agreement is disheartening. This unethical act by government had been repeated time and again, and it negates the moral path of honour, integrity and nobleness of character. This action by the state have over the years been a source of igniting industrial unrest in Nigeria with time wasted in renewed negotiation, or with consequence for prolonged delay in implementing agreed conditions of service. The theoretical arguments that necessitate moral action in government relations with her employees are neatly tied to four ethical demands which are: duty-base, virtue-based, principle-based and consequential approaches. According to Denhardt and Denhardt, (2009:134) the ultimate goal of these approaches is the development of virtue and the application of sound ethical reasoning to resolving public problems. This is essential for improving and utilizing employee competences as well as strengthening in employees a sense of responsibility to their employer and to the people they serve. 
The ideals of moral action is drawn from the long standing tradition that demands putting principles (whether utilitarian, deontological, or any other) into action is associated with the development of "character" ... which requires more than abstract knowledge to actual application of virtues. It requires that the administrator does not simply know how to apply given principles, but should bring moral judgments to bear in the "real world" (Denhardt and Denhardt, 2009:133) that strengthens honesty, courage, and trustworthiness to kindness, fairness, and dependability. As such, instilling in governmental and administrative system and their relations the spirit of moral action would eliminate the recalcitrant character of government reneging on joint agreement and the equally unethical failure of some public administrators to deliver public services in unsatisfactory fashion.

The persistent strike by ASUU and her other sister unions, the only suspended polytechnic academic and nonacademic staff strike, and the equally just called-off strike by health workers nationwide are painful example of government insincerity and lack of moral rectitude in dealing with some section of its employees. In the face of such discrimination, dishonesty and distrust, a moral case can then be built to influence government to act in ways that is morally consistent with good ethical standard of honest, virtue and integrity of character by abiding by agreed terms of agreements. This is the essence of putting moral action into practice. A moral action is defined as one that is determined by reason, not by sensual impulses. Because an action is moral on account of it being reasoned, the moral worth of an action is determined by its motive, or the reason behind the action, not by its consequences. We can determine the worth of the motive behind any given moral action by asking whether we could turn that motive into a universally applicable maxim. Reason is the same at all times and for all people, so morality too should be universal. Therefore, an action is moral only if it embodies a maxim that we could will to be a universal law (Sparknotes, 2013).

The question here is why has government relations with some section of its employees failed to reflect this maxim? It is not a strange story in Nigeria to note that government relations with its employees have significantly breached the above standards. If government fails to uphold the right moral value why should public employees develop any sense of responsibility to the state or the citizen? It is not out of place to observe that under such government-employee discord employees tend to subvert management goals (Wilkinson, 2001:515) by ensuring that either by malfeasance, nonfeasance or misfeasance public service delivery declines significantly to a totally unacceptable level. Locating public employees' reaction to inequitable treatment within the precinct of the equity theory (Jonathan, 2006:193) their subversive action may be judged right but if placed on the ethical scale they are found wanting and their action is not only wrong but unacceptable. The evident impact of such abandonment of the right sense of responsibility to the public by public sector workers has severely fallen disproportionately on the helpless citizens as public institutions have simply failed to serve the Nigerian people as expected (Leadership, 2013:3).

Although, the pressures on government to respond to demands for fairness by trade unions in the face of declining public resources is a pretty difficult situation to be in; especially one that has to do with setting and implementing a fair wage regime for all group in the public service. This challenge nevertheless, competence and ethics in the workplace demands the best combination of efficiency and justice (Derek, et al., 2005:724). Unfortunately, the search for efficiency for Nigerian public service has neglected the justice dimension. The process of demanding for a fair wage regime has been wrongly politicized to the detriment of those who do not have access to government. Even though Nigerian government acknowledges that public civil servant in Nigeria generally receive low pay (Okonjo-Iweala and OsafoKwaaka, 2007:14). That should not be the case as the aphorism states what is good for the goose is good for the gander. This position is aptly expressed by Chomsky (2002) and Schivone, (2007) that if we adopt the principle of universality: if an action is right (or wrong) for others, it is right (or wrong) for us. Those who do not rise to the minimal moral level of applying to themselves the standards they apply to others more stringent ones, in fact-plainly cannot be taken seriously when they speak of appropriateness of response; or of right and wrong, good and evil...in fact, one of the, may be the most, elementary of moral principles is that of universality, that is, if something's right for me, it's right for you; if it's wrong for you, it's wrong for me. Any moral code that is even worth looking at has that at its core somehow (in Wikipedia, 2013)

One cannot discard the fact that telling the truth is fundamental for building public trust; public trust is a veritable instrument for garnering public support for legitimating government actions. It is evident that trust is central to legitimate democratic government, to the formation of public policy, and to its implementation (Grover, 2008:165). According to Wikipedia, (2013) political morality is relevant to the behaviour of national government, and to the support they receive from their host population. Its usage by the government has failed to promote the needed support for government in Nigeria. It is due to this failure that the Nigerian government has resort to lies and unhealthy schemes in relating to her employees to survive. The question then is why does government lie to its employees when it knows it is not ready to fulfill some of its contractual obligation to them? Theoretically, several reasons can be adduced to answer the question why government engage in deception; those reasons are: i) to hide poor performance, ii) arrogance, iii) the uncomfortable nature and consequences that follows telling the truth and iv) private gain masquerading (Grover, 2008:166 \& 167) in the 
name of public interest.

The whole issue rest simply in the lack of proper political ethics or the inappropriate application of the principles of political ethic. While political ethics is to some degree inevitable, Max Weber however reminds us that political ethics cannot base itself solely on motivation only but has also to take account of the consequences of decisions. That is, with responsibility (Benoit, 2012:31). Basically the government even in the face of its amoral nature and ineptitude to regulate a balance has also failed to be responsible for its action or inaction. Rather, the state has resorted to deception of the public to cover for her inadequacies. It then follows that Nigerian government engage in deception to hide her incompetence to regulate a balance wage and salary regime, this failure does not align with the purportedly public interest reason. Using deception to cover this weakness is a slippery slop; when government or public official starts using this rationale (in this case deception) for issues of greater moments, might over time, start applying them to virtually all issues. Lying becomes habitual; a standard operating procedure (Grover, 2008:167). It is under this pretext that the Nigerian government has gotten itself covered in the mire of insincerity such that any negotiated agreement with its employees is handled by the latter and the general public with a pinch salt.

To remedy the poor character of dishonesty that has caused the distrust of government and the associated amoral action of its public institutions will require the government to first adjust to the higher ethical standard of moral action. Moral action is not an informal system that has no authoritative judge and no decisional procedures that provide a unique guide to action in all situations. It is for this reason that it is necessary for both the government and its employees to exercise moral judgement. The ability to exercise judgement when making difficult decisions is an important quality because consistently paying attention to issues of ethics and judgement will cause the quality of public service delivery to improve over time (Kanyane, 2010:81). In the absence of this, it is important for concerned groups during periods of making critical decisions to use the right political and legal systems to supplement morality. Although, formal systems have the means to provide unique guides, but they do not provide the uniquely correct moral guide to the action that should be performed (Stanford encyclopedia of philosophy, (2002) given that most administrative actions despite being authorized by law is dependent on the individual discretion (Meyers and Vorsanger, 2007:154) of the implementing officer and not necessarily dependent on the intra-bureaucratic operational modes (Mohit, 200:432) to right effect that responsibility adequately.

The challenge is not only derived from avoiding the obvious consequence of being unfair but also to strengthen and increase the already depleted level of morality in a society whose government's savings in the bank of ethics is significantly very low. Equally too, there is the need to ensure that differences are narrowed so that services are not disrupted and conflicts are greatly minimized. Resolving conflict arising from the issues of discrimination it is expected of the government be open, tell the truth, keep their promise and respect the dignity of the individual. It is by doing so that the action of the government could be justified as consistent with the shared sense of moral order, which the administrator should feel strongly compelled to act in that way (Denhardt and Denhardt, 2009:130) that is equally reciprocal. This observation is instructive given that all permutations dictates that there are certain underlying rules according to which behavior is judged, and no matter how desirable the consequences, there are certain things the manager (and government) may not do (Lewis, 2007:526). That is, not acting contrary to the duty-based principles of benevolence, paternalism, harm, honesty, lawfulness, justice and social benefit.

This paper is not oblivious of the fact that the actions of administrators is shaped by different influences which put together define their moral foundation and drive them to act in the most appropriate manner such that the interest of the government, the administrator and the public is served without undermining anyone in the relationship. Sadly, this is not often the case. It is evident that this demand may be a tall order given that the value preference and specific goal of the three actors may differ even though it is presumed that their interest should converge at ensuring better service to the citizenry. Theoretically, the goal of the government is to serve the public interest through the use of public resources in an efficient manner. The administrator's focus is to provide the right service to the public as dictated by public policy in accordance with regime value that is regulated by laws and rules, and the constitution (Mohit, 2006:432). It is also expected that in delivering public service the elements of honour, benevolence and justice taken together should constitute the moral foundation of the public administrator (Mohit, 2006:431). It is also required that the administrator should respond to the demand of accountability to the elected superior (Ozor, 2000:324) in as much as the government is to be politically accountable to the governed (Ogban-Iyan, 2000:28).

The public as citizens expect the government and the administrator in the discharge of their responsibility to them to function within the large framework of societal culture, public interest and ethical neutrality. On the contrary, ethical neutrality as Mohit, (200:430) noted seeks to the consequence of action; this in itself contradicts, if not, obliterate the scared demand of accountability to the people by blurring the capacity to specifically hold one individual responsible given the interrelated nature of roles in public organizations. Where such is the case, the very essence of administrative 
responsibility is compromised. It should not also escape our mind that one of the cardinal values of efficiency is to minimize cost for which increase in salaries of wages of employees represent increased cost for the state.

What ever is case, if the government fails to pay its public employees salaries and wages that are deemed fair but pay her political office holders better remuneration it is then evident that the demand of categorical imperative and the maxim of universality is fractured. Categorical imperative demand that we must act in such a way that we could will the maxim according to which we act to be a universal law. If however the government is unable to act rightly even when the law makes provision for her to act so because of the need to be efficient in the use of resources then such action creates room for administrator to shirk or to act in malfeasance, misfeasance or nonfeasance (Grover, 2008:168 - 9) manner given that the government has failed to recognize the universality of moral law which applies equally to all people. Acting morally, then, requires that we recognize other people as moral agents and always treat them as ends in themselves, not as means by which we can achieves our own ends (Sparknotes, 2013).

\section{Conclusion}

In every civilize society, it is expected that government lead by example. It is only when the government begins to act morally right that it will engender the spirit of "patriotism of benevolence" from its employee to act in the public interest in accordance with the dictate of optimism, courage, and fairness tempered by charity and the love for other (Mohit, 200:430) citizens by delivering the right qualitative and quantitative service. It is however apposite to note that these ingredients seem to be significantly lacking in most Nigerian public employees. This has sparked-off criticism from both the public and government domains that their public employees and the institutions they administer are grossly inefficient. This is not to say that Nigerian public officials lack the capability of imbibing and sincerely espousing ethical standards in public service but they are however demotivated by political forces. It is because of the continued failure of our political leaders in government to align their actions in harmony with high ethical standards.

Sadly, the public in its desire for efficient service have failed to look deep and hard to identify the root cause of public employees' dysfunctional performance in the public place. It is foolhardy to assume that some of Nigeria's public employees are to be totally exonerated from been partly responsible for its present predicament, it is however evident that the challenge of 'incompetence' facing the public service is associated with the negative external environmental force exerted by elected political hands in government. It will be out of place to observe that Nigerian public employees are oblivious of the need to adhere to the ideals of administrative responsibility and moral action to the citizens and the state in the right measure in the discharge of their constitutional responsibility. It is however necessary to correct those environmental forces that have demotivated and undermine their desire to strive for better service delivery that is in tune with a spectrum of normative principles derived from both consequentialist and duty-based approach.

It is however saddening to note that while our representative allocate to themselves generous pay package in unethically manner they have on the contrary erected unwholesome speed-breakers that will undermine any effective determination and implementation of a fair wages and salaries regime for its public employees in Nigeria. The disturbing consequence of such self-centric action is that most of our public officials are not motivated to work, triggered brain-drain, provoked poor work ethics, and high cost of obtaining privately provided services that ought to have been provided cheaply through public institutions. The cumulative effect is that even when public organizations provide such services access to them is difficult and the quality level is disgustingly poor, and supply, few and far between due to intermittent and unnecessary strike-induced work stoppages. Associated with the above situation is the fact that our public resources are on a constant basis being pouched on with impunity by public officials to make-up government failure to timely and rightly compensate her public employee.

It is from this angle that the public see public organizations as contributing in subverting the presumed development effort of the Nigerian state. On the whole, the burden of irresponsive governance is reflected in the lack of sincerity to service delivery and the gross decline in public employee work ethics in Nigeria's public organizations. The evident burden of this decline is bearing heavily on civil common that are unable to access those necessary service. To this paper, the Nigerian civil service system should not be wholly held responsible for the underdevelopment of the country (Adamolekun, 2006:128), rather, the government' amoral actions should be fingered as the as the root of the nonperformance of the various government (IDEA, 2000:140).

It is against the backdrop of this unacceptable outcome that the process of reengineering must start with the government that has created the enabling environment for her employees to act immorally in ways that continues to fracture the higher standards of administrative responsibility and moral action in the public place. It is only when such reengineering begin with the government that public service values and duties will reflect a mixture of institutional arrangements (such as accountability), instrumental values (like efficacy) fundamental or ontological values (like honesty, 
fairness etc.) (Mohit, 200:430) will intermingle to form a solid foundation for better work ethics necessary for strengthening employee's and public organizational competence for better service delivery to Nigerians.

\section{References}

Adebayo, A (2000) Principles and Practice of Public Administration in Nigeria (2nd ed). Ibadan: Spectrum Books Limited.

Adamolekun, L (2006) Politics and Development in Africa. Ibadan: Spectrum Books Limited.

Akume, A. T (2012) Public Organizational Development and Change: A Comparative Re-Visit of the Udoji and the 1988 Civil Service Reforms in Nigeria. In: Nigerian Journal of Social and Development Issues, Vol. 6. No. 2. Pp. 29-45.

Bartol, K, M and Martin, D. C (1998) Management (3rd ed.). Boston, MA: McGraw Hill. Benoit, G (2012) Ethics In Politic: Why It Matters More Than Ever And How It Can Make A Difference. Globethics. Net Focus No. 5.

Boam R and Sparrow, P, R (1992) The Rise Of And Rationale Of Competency-Based Approach. In: Boam R and Sparrow, P, R (eds) Designing And Achieving Competency: A Competency Based Approach To Developing People And Organizations. London: McGraw Hill. Pp. 3-15.

Boyatize, R. E (1982) Management Competencies Retrieved On The $7^{\text {th }}$ September, 2013 from changingminds.org/disciplines /leadership/actions/boyatize_competencies.html

Caplan, R. D (1987) Person-Environmental Fit Theory and Organizations: Commensurate Dimensions, Time Perspectives, and Mechanism. In: Journal of Vocational Behavior, Vol. 31. Pp. 248-267.

CIPD, (2013) Competence and Competency Frameworks. Retrieved March 11, 2013 from www.google.com

Cole, G. A (2004) Management Theory and Practice (6 $6^{\text {th }}$ ed). London: Thomson Powerbooks.

Civil Service human resources, (2013) Civil Service Competency Framework, 2012-2017. Retrieved September 1, from www.google.com

Cray, D (2001) Culture. In: Poole, M and Warner, M (eds) The IEBM Handbook of Human Resources Management. London: Thomson Learning. Pp.3-8.

Denharht R. B and Denhardt, J. V. (2009) Public Administration: An Action Orientation (6 $6^{\text {th }}$ Ed) Belmont, CA: Thomson Higher Education. Derek, T., Hall, L and Stephen, T (2005) Human Resource Management (6 $6^{\text {th }}$ ed). London: Pearson Educational Limited.

Ezekwesili, O (2013) National Assembly, Cost Of Governance and the \#1trn Question. Retrieved September 7, 2013 from ilevbare.com

Gilbert, C. E. (1959) The Framework Of Administrative Responsibility. The Journal of Politics. Vol. 21. Issue 3 August, Pp. 373-407.

Gold J (1999) Planning and Selection. In: Brantton, J and Gold, J (eds) Human Resources Management: Theory and Practice. London: Macmillan Business. Pp. 163-188.

Grobler, P. A., Warnich, S., Carrel, M. R., Elbert, N. F and Hatfield, R. D 2002) Human Resource Management in South Africa (2nd ed). London: Thomson Learning.

Grover, S (2008) Managing the Public Sector (8th ed). Boston, MA: Thomson Higher Education.

Guardian, (2013) CSOs Decry Nigeria's Governance Structure, Poor Leadership, Guardian, Thursday 29, August, 2013.

Guy, B and Balfour, D. L (2007) In the Face of Administrative Evil: Finding a Basis for Ethics in the Public Service. In: Shafritz, J. M and Albert, C. Hyde (eds) Classics of Public Administration (6th ed).Boston, MA: Thomson Higher Education. Pp. 566-576.

Heywood, A (2006) Politics (2nd ed). New York: Palgrave Foundation.

Haque, A (2004) Ethics And Administrative Discretions In A Unified Administration. In: Administration and Society, Vol. 35. No. 6. Sage Publication.

Heller, F 2001:331 Work Ethic In: Poole, M and Warner, M (eds) The IEBM Handbook Of Human Resources Management. London: Thomson Learning.

Henry, N (2007) Public Administration and Public Affairs (10 thed). New Delhi: Prentice Hall Of India.

Herbert, A. S (1941) The Proverb f Administration. Public Administration Review, Vol. 6. No. 1. (Winter), Pp. 53-67.

Hood, C (2007) A Public Management for All Seasons? In: Shafritz, J. M and Albert, C. Hyde (eds) Classics of Public Administration (6 $6^{\text {th }}$ ed).Boston, MA: Thomson Higher Education. Pp.495-507.

IDEA, (2000) Democracy in Nigeria: Continuing Dialogue(s) for Nation Building. Capacity-Building Series 10. Stockholm: Sweden.

lyayi, S. A (2004) Bureaucratic Reforms and Development in Nigeria. In: Bello-Imam, I. B and Obadan, M. I (eds) Democratic Governance and Development Management in Nigeria's Fourth Republic 1999-2003. Ibadan: CLGARD. Pp. 282-300

Juha, L and Gyursanszky, K (1998) Intra-Organizational Impediments to the Development of Shop floor Competence and Commitment: The Case of a Finnish-Owned Greenfield Paper Mill in East Germany. In: International Journal of Human Resource Management, Vol. 9. No. 2. Pp. 259-273.

Kanyane, H. M (2010) Public Service Delivery Issues in Question. In Kwandiwe, K and Mashupye, H. M (eds) The Zuma Administration: Critical Challenges. Pretoria: HSRC Press. Pp. 77-94.

Jonathan, L (ed) (2006) Oxford Dictionary Of Business and Management (4ed). New York: Oxford University Press.

Leadership, (2013) The Civil Service Needs Urgent Reform. Leadership Newspaper, Friday September 13, 2013.

Lewis, C. W (2007) The Ethics Challenge In Public Service. In: Shafritz, J. M and Albert, C. Hyde (eds) Classics of Public Administration (6 $6^{\text {th }}$ ed).Boston, MA: Thomson Higher Education. Pp. 524-550.

Meyers, M. K and Vorsanger, S (2007) Street-Level Bureaucrats and the Implementation of Public. In: Guy, P and Pierre, J (eds) The Handbook Of Public Administration. London: Sage Publication Policy Limited. Pp.153-164.

Miller, S. M (2013) Agency Leader Selection and Bureaucratic Competence: The Effect of Elected Agency Executives. Being a Working 
Draft Prepared For Public Management Research Association Conference. Madison, WI. Pp. 1-24

Mohit, B (2006) New Horizon of Public Administration. New Delhi: Jawahar Publishers and Distributors.

Nnaji, E, N (2000) The Legal/Statutory Framework For Public Accountability In Local Governments In Nigeria. In: Ozor, E (ed) Public Accountability: Financial Management in Local Governments in Nigeria. Enugu: Lizzibon Publishers. Pp.79-96.

NPC, (2012) A Single Competency Framework for All Prescribers. Retrieved March 11, 2013 From www.google.com

Odewale, T (2013) Ezekwesili, NASS Tango over N1trn Allocation. Daily Newswatch Friday August 30, 2013.

Ogban-Iyan, O (2000) The Need for Public Accountability in Three Tiers of Government in Nigeria. In: Ozor, E (ed) Public Accountability: Financial Management in Local Governments in Nigeria. Enugu: Lizzibon Publishers. Pp. 27-37.

Okonjo-Iweala, N and Osafo-Kwaako, P (2007) Nigeria's Economic Reforms: Progress and Challenges. Working Paper \#6 Brooking Global Economy and Development.

Otobo, E (2002) Nigeria. In: Adamolekun, L (ed) Public Administration in Africa: Main Issues and Selected Country Studies. Ibadan: Spectrum Books Limited. Pp. 292-310.

Punnet, B. J (2001) Culture, Cross-National. In: Poole, M and Warner, M (eds) The IEBM Handbook of Human Resources Management. London: Thomson Learning. Pp. 9-26.

Robinson, M. A., Sparrow, P. R., Clegg, C and Birdi, K (2007) Forecasting Future Competency Requirement: A Three Phase Methodology. In: Personnel Review, Vol. 36, No. 1. Pp.65-90. Emerald Group Publishing Limited.

Rosenbloom, D. H., Kravchuk, R. S and Clerkin, R. M (2009) Public Administration: Understanding Management, Politics, and Law in the Public Sector ( $7^{\text {th }}$ ed). New York: McGraw Hill.

Sapru, R. K (2008) Administration Theories And Management Thought (2nd Ed). New Delhi: Prentice Hall Of India.

Sparknotes, (2013) Immanuel Kant (1724-1804) Critique of Practical Reason and Groundwork For Metaphysic of Moral retrieved September 1rst, 2013 from m.sparknotes.com/philosophy/kant.

Stanford Encyclopedia of Philosophy, (2002) The Definition of Morality. Retrieved September 1, 2013 from plato.stanford.edu/entries /morality-definition/).

Schieltz, M (2013) Types of Competency Model. Retrieved On September 7, 2013 from www.smallbusiness.chron.com/typescompetency-model15377.html.

Stekelenburg, J.A.W Van (2012) Exploring Organizational Agility and the Added Value of Human Resources: Creating Organizational Agility by Using Individual Competencies and Organizational Practices. Being A Master Thesis on Human Resources Submitted to The School of Social and Behavioral Sciences, Tilburg University. (Unpublished).

Thompson, J. L (2004) Strategic Management (4th ed). London: Thomson.

Thompson, D. L (2007) The Possibility of Administrative Ethics. In: Shafritz, J. M and Albert, C. Hyde (eds) Classics of Public Administration (6 $6^{\text {th }}$ ed). Boston, MA: Thomson Higher Education. Pp. 451-459.

University of California (2013) A Reference Guide for Academic and Administrative Personnel: Administrative Responsibilities Handbook. Accessible at http://accounting.ucdavis/refs/handbook.cfm.

Wayland, F (2013) Elements of Moral Science. Retrieved on September 1, 2013 from www.lonang.com/exlibris/wayland/wayl-112.html.

Wikipedia, (2013) Morality. Retrieved on September 1, 2013 from en.m.wikipedia.org/wiki/Morality. Wilkinson, a (2001) empowerment. In: Poole, M and Warner, M (eds) The IEBM Handbook Of Human Resources Management. London: Thomson Learning. Pp. 507-517. 